\title{
Investigation of the Thermal Tension of the Bearings of the Crankshaft of an Internal Combustion Engine
}

\author{
${ }^{1}$ Ilnur R. Akhmetzyanov, ${ }^{2}$ Vyacheslav N. Nikishin, ${ }^{3}$ Elena P. Barylnikova, ${ }^{4}$ Oleg A. Kulakov \\ ${ }^{1-4}$ Kazan Federal University \\ Email:692401@mail.ru
}

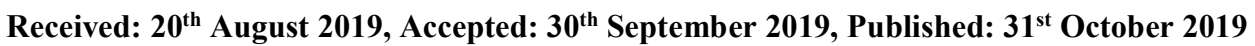

\begin{abstract}
Plain bearings limit the performance of the crankshaft of an internal combustion engine (ICE) to major repairs. Their reliability is determined by heat resistance, wear-resistance and endurance limits of the materials of which the bearing is made. Dynamic loads reduce bearing life. Plain bearings, heavy-loaded and operating at a high rotational speed of the crankshaft, require a constant supply of oil under pressure to maintain the hydrodynamic friction mode and to remove heat generated during friction. In the hydrodynamic regime of friction, heat generation is determined by the viscosity of the oil, the thickness of the lubricating layer, and sliding speed. In operation for plain bearings, it is necessary to provide liquid lubrication at all established operating modes of the internal combustion engine. The oil in the gaps between the neck of the crankshaft and the liner should come under the action of the necessary overpressure, thereby ensuring: complete separation of the working surfaces of the contacting parts of the bearings of the crankshaft during operation; lack of direct friction between the metal surfaces of the shaft and bearing; insignificant value of the coefficient of friction; low friction and heat loss. The paper presents the results of studies on the impact of operational changes in lubrication conditions on the thermal tension of the connecting rod bearings of the crankshaft.
\end{abstract}

\section{Keywords}

Temperature of the Elements of the Crankshaft Bearings, Oil Supply Conditions, Pressure, Hydrodynamic Friction, Sliding Bearing, Internal Combustion Engine.

\section{Introduction}

The crankshaft is one of the main parts of an internal combustion engine that determine its resource. In operation, the most characteristic defect of the crankshaft is a malfunction of mating tribes (the neck of the crankshaft bearings). Analysis of domestic engines received for overhaul shows that the most common cause of engine failure is the scoring of connecting rod bearings $[1,2,3,4]$.

Crankshaft bearings only work reliably under fluid friction conditions. The main hydraulic parameters of the engine lubrication system that determine the reliability of the bearings are pressure and oil flow [4,5]. These two parameters depend on each other, as well as on the viscosity of the oil and the gaps in the tribe-mating "neck-insert shaft" $[6,7,8]$

$$
Q=\xi \cdot \Delta \cdot d^{2} \cdot \omega+A \cdot \frac{P \cdot \Delta^{3}}{2 \cdot \mu \cdot l},
$$

where $Q$ - oil consumption; $\xi, \mathrm{A}$ - experimental coefficients; $\Delta$ is the diametrical clearance in the bearing; $d$ - shaft diameter; $\omega$ is the angular velocity of rotation of the shaft; $P$ - oil pressure at the inlet to the bearing; $\mu$ is the dynamic viscosity; $l$ - half the working length of the bearing.

If the pressure of the oil supplied to the bearings is insufficient, the conditions of hydrodynamic friction may be violated, as a result of which the thickness of the oil layer may become lower than critical, which increases the likelihood of turning the liners [9].

Due to the low oil consumption through the bearing, as well as its temporary cessation, heat removal to the oil is reduced, which can lead to overheating of the bearing, as well as a large temperature gradient relative to the working and back surfaces of the liner. Thus, due to dry friction, a temperature of about $320^{\circ} \mathrm{C}$ is created on the surface of the bearing, as evidenced by the "color tint" from violet to gray. As a result of high temperature, the liner enters an overstressed state, acquires deformations [10], loses its shape, the bearing gap is selected to zero, the surfaces of the liner and neck are set, the friction forces in the contact increase and, overcoming the existing forces of resistance to rotation, the liners rotate.

\section{Methods}

A sharp increase in heat dissipation in bearings and the beginning of an intensive increase in oil temperature contributes to the violation of the hydrodynamic friction regime.

The following method has been proposed [11] for assessing the thermal state of bearings and studying ongoing processes. The thermal stress of the bearing is estimated by the temperature, which can be measured using chrome-alum thermocouples. Thermocouples on the surface of the liners are located in the central most loaded zone. The thermocouple installation diagram is shown in Figure 1. 


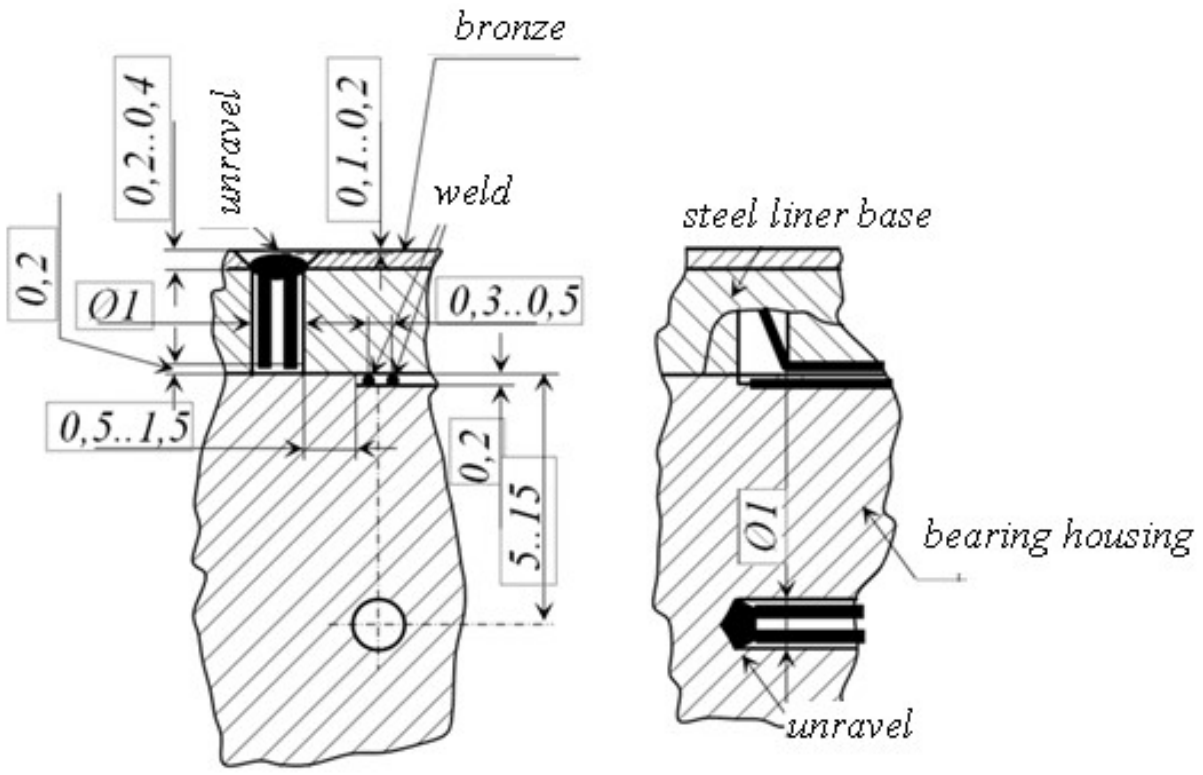

Figure 1: The Scheme of Embedding Thermocouples in the Liner and the Bearing Housing

To assess the direction and magnitude of the heat fluxes, thermocouples are additionally installed in the bed and bearing housing. In the bearing housing for the V8CH12 / 12 diesel engine, thermocouples can be located at a distance of 5, 10 and $15 \mathrm{~mm}$ from the bearing bed. The signal output from the connecting rod thermocouples is made through the lever current collector. The layout of thermocouples is shown in Figures 2 and 3.

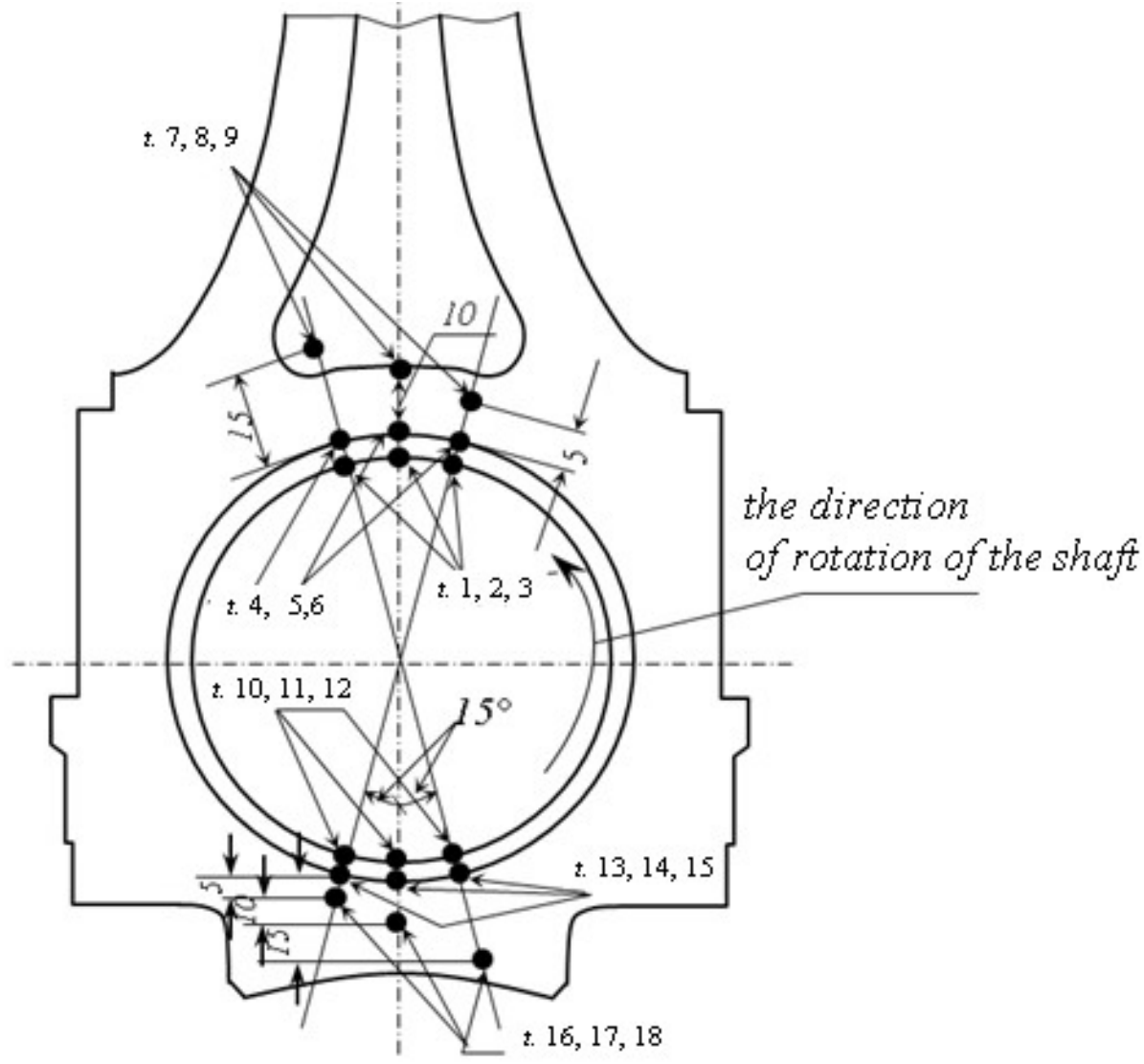

Figure 2: The Layout of Thermocouples in the Bearing and Connecting Rod (t. 1,2,3, .., 17, 18 - thermocouple numbers) 


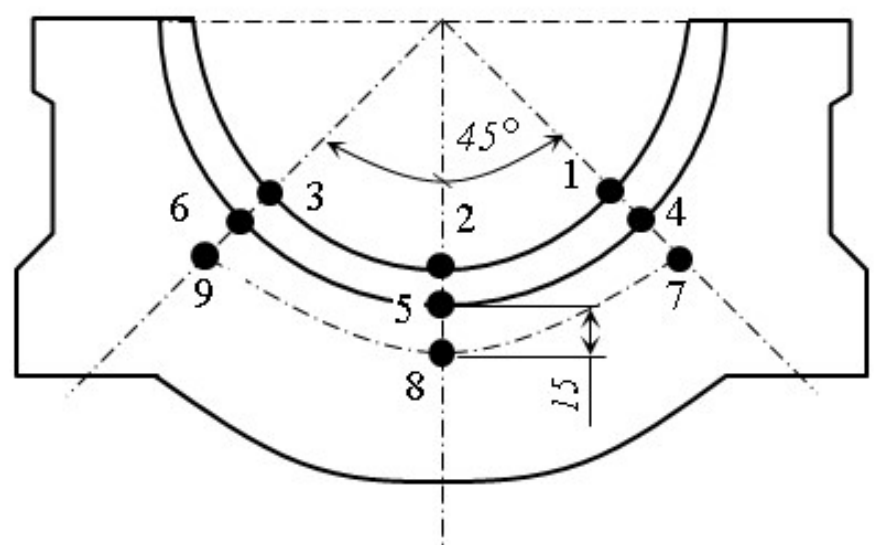

Figure 3: The Layout of Thermocouples in the Cover of Native Support

$(1,2, \ldots, 6,9$-thermocouple numbers)

In addition to measuring the temperatures of the liner, it is necessary to provide a measurement of the parameters of the oil supplied to the bearing, such as temperature, flow rate, and pressure. To do this, the design of the lubrication system is being finalized. In order to individually supply oil to the main bearing under study via existing channels, the remaining consumers are "fed" through additional channels. To regulate and control the oil supply on the oil pipe, throttle and oil flow and pressure sensors are installed. Chromel-alumni thermocouples are also used to measure oil temperature.

In studies, nominal clearances are established in the main and connecting rod bearings: for a diesel engine 8CH12 / 12, the diametrical clearance in the connecting rod bearing should be $0.074 \mathrm{~mm}$, and in the main bearing $-0.112 \mathrm{~mm}$.

During bench tests, the dependences of the temperature of the connecting rod and main bearings on the high-speed, load operating modes of the diesel engine, the temperature and pressure of the oil at the inlet to the main bearing are determined.

\section{Results and Discussion}

Conducted by research methods showed the following results.
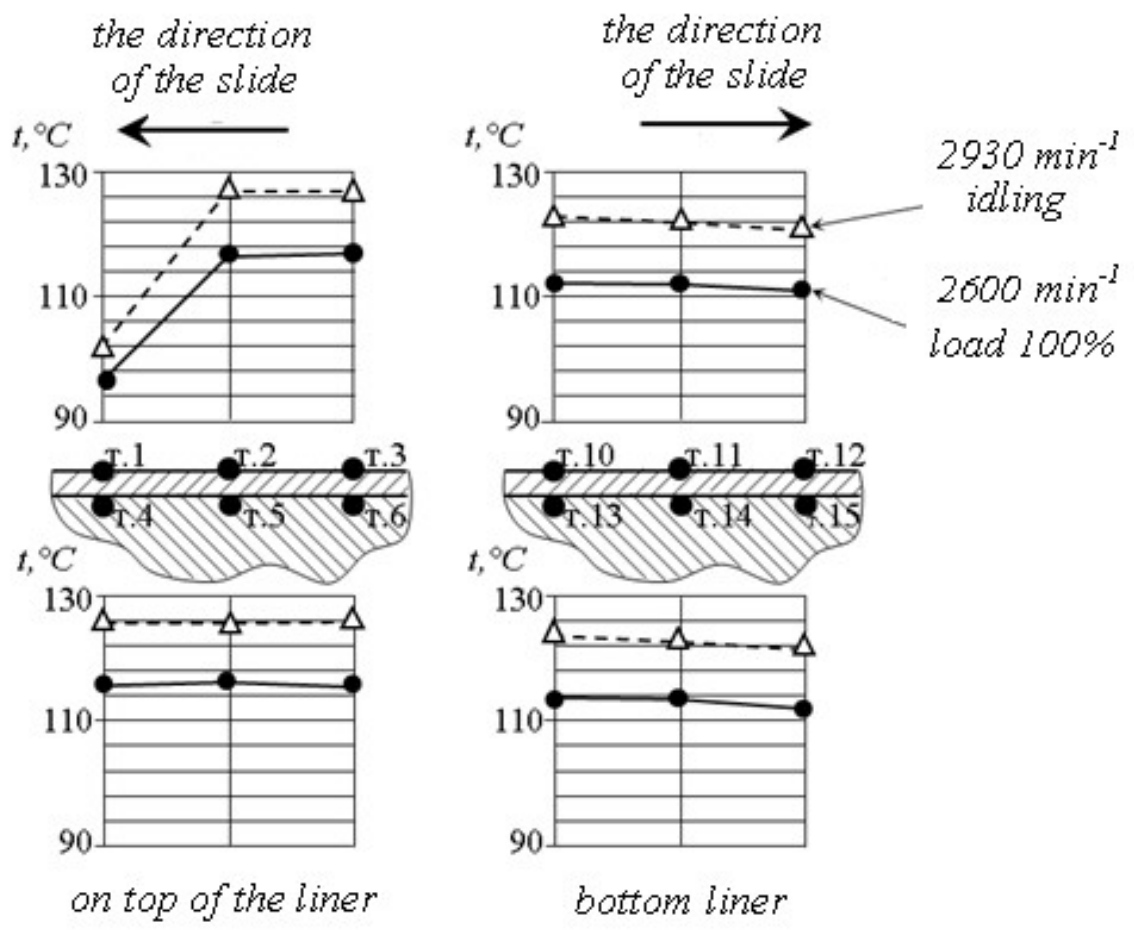

Figure: The Temperature of the Connecting Rod Liners 
In fig. 4 shows the temperature distribution on the working and outer surfaces of the connecting rod bearings. The temperature and oil pressure are: $t_{\mathrm{m}}=96^{\circ} \mathrm{C}, p_{\mathrm{m}}=3.7$ bar. The difference in temperature between the working and external surfaces does not exceed $1.5 \div 2^{\circ} \mathrm{C}$ and remains at the entire high-speed mode of operation of the diesel engine. Therefore, average temperatures on the working surface of the liner will be presented below. The temperature of the liners depends on the crankshaft speed, which follows from Figure 5.

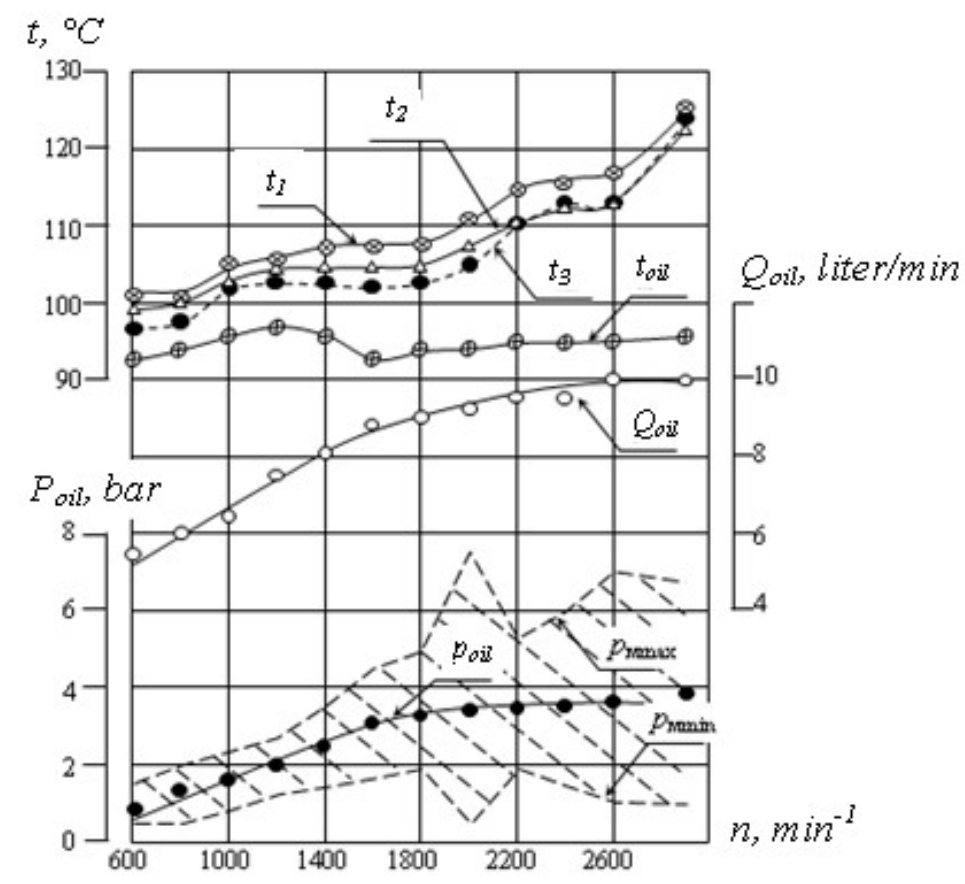

Figure 5: The Dependence of the Temperature of the Working Surface of the Inserts and the Parameters of the Oil Supply when the Diesel Engine on the External Speed Characteristics

$\left(t_{1}\right.$ - the temperature of the upper connecting rod liner; $t_{2}$ - the temperature of the lower connecting rod liner; $t_{3}-$ the temperature of the bottom liner; $\mathrm{t}_{\text {oil }} ; \mathrm{p}_{\text {oil }} ; \mathrm{Q}_{\text {oil }}$ - temperature, pressure and oil consumption respectively)

The temperature of the upper connecting rod bearing is $1 \div 4^{\circ} \mathrm{C}$ higher than the temperature of the lower. The difference increases with increasing crankshaft speed. The temperature of the main liner at low and medium frequencies is slightly lower than the connecting rod inserts, the difference does not exceed $6^{\circ} \mathrm{C}$, at nominal speeds of the crankshaft the temperatures are aligned. The increment of the temperature of the working surface of the liners to the temperature of the oil at the entrance to the main bearing is:

- for the upper connecting rod bearing $7 \div 30^{\circ} \mathrm{C}$;

- for the lower connecting rod bearing $6 \div 26^{\circ} \mathrm{C}$;

- for the lower root insert $4 \div 28^{\circ} \mathrm{C}$.

The maximum temperature of the working surface of the liners, respectively, is equal to $126 ; 122$ and $124^{\circ} \mathrm{C}$.

Consumption $Q \mathrm{~m}$ and average pressure $p_{\mathrm{m}}$ oils increase to approximately $n=1800 \mathrm{~min}^{-1}$. Then the influence of the crankshaft speed on these parameters is insignificant, which is due to the operation of the differential valve of the oil pump.

The installed oil pressure sensor made it possible to detect fluctuations in the oil pressure in the oil line at the inlet to the main bearing.

A sample pressure waveform is shown in Figure 6. 


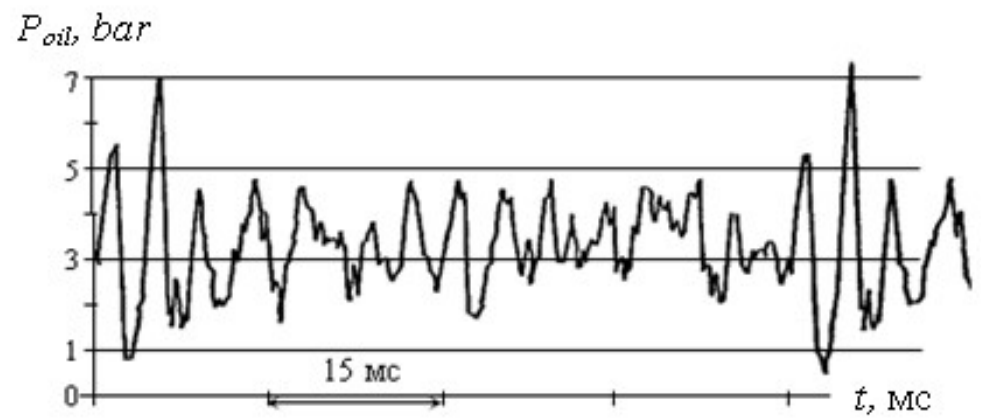

Figure 6: Oscillogram of Oil Pressure Fluctuations at the Inlet of the Main Bearing $\left(\mathrm{n}=2000 \mathrm{~min}^{-1}\right.$; load $\left.100 \% ; \mathrm{t}_{\mathrm{oil}}=94^{\circ} \mathrm{C} ; \mathrm{p}_{\mathrm{oil}}=3.3 \mathrm{bar}\right)$

Waveform processing is performed at the maximum $p_{\mathrm{mm} \text { max }}$, the minimum $p_{\mathrm{mm}}$ and the average $p_{\mathrm{m}}$. The results of this analysis are shown in Figure 5. It follows that the double amplitude of pressure fluctuations $\left(p_{\operatorname{mm} \max }-p_{\mathrm{mm} \min }\right)$ is in the range from 0.9 to 6.9 bar, respectively, at 600 and $2000 \mathrm{~min}^{-1}$. In the entire range of diesel engine crankshaft speeds, the minimum oil pressure varies from 0.5 to 1.8 bar, the maximum from 1.4 to 7.4 bar.

The change in bearing temperature due to engine load is weak. When the load changes from 0 to $100 \%$, the temperature of the working surface of the liner changes by $3 \div 5^{\circ} \mathrm{C}$. The average oil pressure is independent of engine load.

It was experimentally established that the temperature of the liners is directly proportional to the oil temperature (Fig. 7). At the same time, for every $10^{\circ} \mathrm{C}$ increment of the oil temperature, the increment of the liner temperature is $8.5 \div$ $9.0^{\circ} \mathrm{C}$. The temperature of the liners at an oil temperature of $120^{\circ} \mathrm{C}$ is equal to:

- $\quad$ upper connecting $\operatorname{rod}-140^{\circ} \mathrm{C}$;

- lower connecting rod $-136^{\circ} \mathrm{C}$;

- $\quad$ lower radical $-139^{\circ} \mathrm{C}$.

Oil consumption with increasing oil temperature from $70^{\circ} \mathrm{C}$ to $110^{\circ} \mathrm{C}$ smoothly increases from 7.8 to $9.6 \div 101 / \mathrm{min}$. With a further increase in oil temperature, the flow rate does not change. The average oil pressure at the inlet to the main bearing decreases linearly from 4 to 3.1 bar with increasing oil temperature. At the same time, the double amplitude of oil pressure fluctuations decreases from 6.9 to 4.6 bar. The minimum oil pressure also rises.

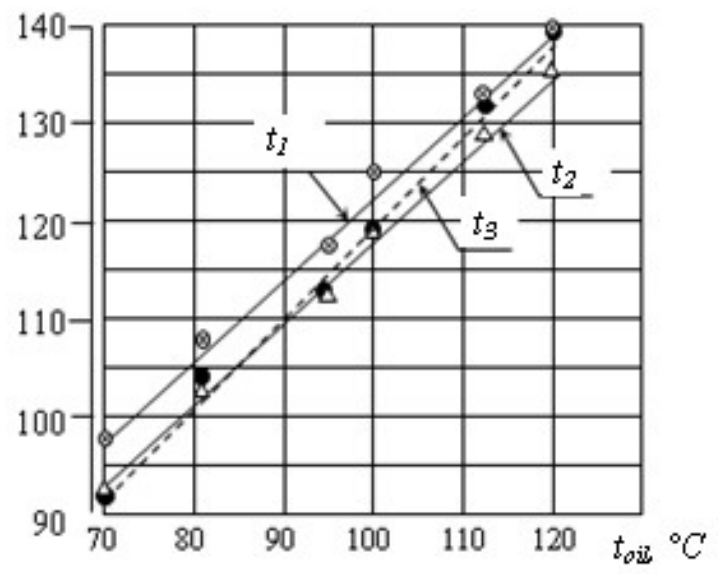

Figure 7: The Dependence of the Temperature of the Working Surface of the Liner on the Oil Temperature at the Inlet of the Main Bearing: Nominal Mode

$\left(t_{1}\right.$ - the temperature of the upper connecting rod liner; $t_{2}$ - the temperature of the lower connecting rod liner; $t_{3}-$ the temperature of the bottom liner)

The next parameter analyzed is the dependence of the linear temperature on the oil pressure at the inlet of the main bearing. Dependences of the temperature of the liners on the oil pressure can be obtained at various oil temperatures, for example, $70 ; 95 ; 110$ and $120^{\circ} \mathrm{C}$. Figure 8 shows the dependencies at oil temperatures of 70 and $110^{\circ} \mathrm{C}$. 

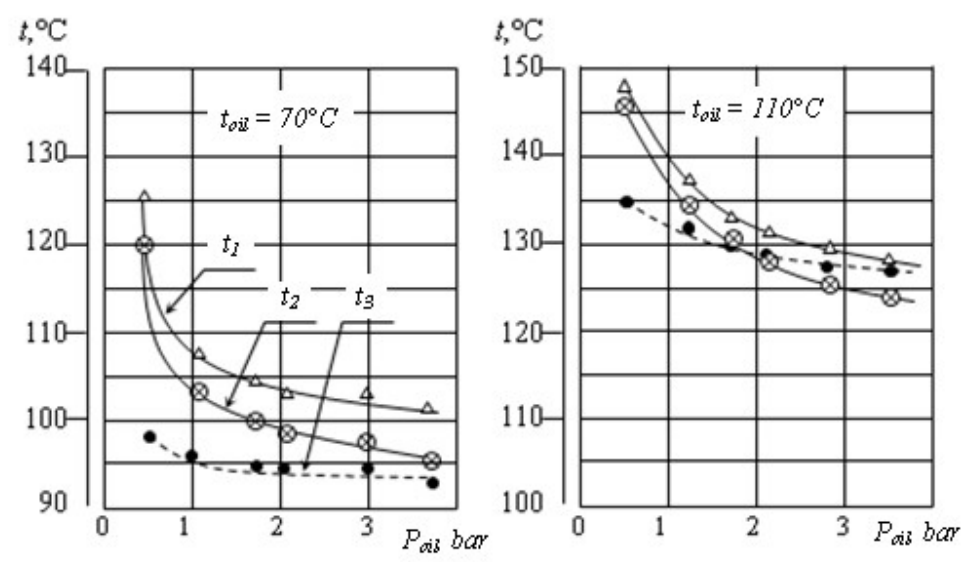
Figure 8: The Dependence of the Temperature of the Working Surface of the Liner on the Oil Temperature at
the Inlet of the Main Bearing: Nominal Mode

( $\mathrm{t} 1$ - the temperature of the upper connecting rod liner; $\mathrm{t} 2$ - the temperature of the lower connecting rod liner; $\mathrm{t} 3$ - the temperature of the bottom liner)

The analysis revealed that when the oil pressure drops below 2.5 bar, the temperature of the connecting rod bearings increases. This boundary for oil pressure is also the boundary of the transition from hydrodynamic friction to dry friction.

When measuring the oil flow through connecting rod bearings, the effect of "pulsation" of the oil flow with the termination and restoration of the outflow was revealed. The effect of "ripple" is a periodic cessation of oil supply, and then an increase in intensity at certain intervals. The duration of the flow rate is 3-4 seconds. This ripple was observed at a crankshaft speed starting from $1600 \mathrm{~min}^{-1}$ and higher.

Depending on the operating oil pressure in the engine lubrication system, the nature of the "pulsation" of the oil flow changes. When the oil pressure decreases from 5 bar to 2.5 bar, the onset of pulsation occurs in the range of the crankshaft speed from $1600 \mathrm{~min}^{-1}$ and higher. The amplitude of the "pulsations" also changes. The frequency of "pulsations" of the oil flow increases with an increase in the engine speed.

When dry friction occurs, the temperature on the surface of the connecting rod bearing increases exponentially (Fig. 8) and reaches about $320^{\circ} \mathrm{C}$, which in these studies could not be measured due to the inertia and averaging of temperature measurements using the method described above. To measure the temperature of the working surface, it is necessary to develop and apply a non-contact method of measuring temperature.

The temperature of the main bearing increases slightly, that is, under these conditions, the hydrodynamic friction regime is still maintained in the main bearing under these conditions.

\section{Summary}

1. The temperature of the connecting rod bearings depends on a decrease in pressure and oil consumption and rises significantly, which indicates a transition from hydrodynamic friction to dry friction.

2. The temperature of the surfaces of the bearings is significantly different from the average temperature measured by the built-in thermocouples in the connecting rod bearing and above by 200 degrees with semi-fluid and dry friction.

3. In connecting rod bearings during operation there is a large temperature gradient between the working and the back surfaces.

4. A large temperature gradient is a reason for the linear temperature expansion of the fibers uneven in thickness and the occurrence of additional stresses other than installation stresses.

5. Summing up with mounting stresses, thermal stresses contribute to reaching and exceeding the yield strength of the steel base of the liner near the working surface, which leads to a shortening of the fibers around the circumference and elongation along the axis of the surface layers.

6. The elongation of the fibers along the axis leads to a shape change in the form of a deflection and a separation of the middle part of the liner during operation from the surface of the connecting rod and deterioration of heat transfer to the connecting rod. In addition, the shaping of the liner violates the ideal cylindricality and, accordingly, the hydrodynamics of the bearing itself.

7. Most of all, the shape change of the liner with the formation of a deflection leads to a decrease in the clearance in the bearing up to its full selection, which is the direct cause of the setting of surfaces and turning of the liners and the final kinetics of the process. No less significant is the deterioration of the thermal tension of the liners as a result of a decrease in oil consumption through the clearance in the bearing due to its reduction to zero. That is, the launched process of shaping itself intensifies itself, which is its kinetics. 
8. The shortening of the fibers along the circumference leads to a shortening of the length of the generatrix of the liner, which in turn reduces the protrusion and interference in the fit of the liners. This helps to reduce the pressing of the liners to the surface of the connecting rod and the moment of friction that keeps the liners from turning.

9. The decrease in pressure and oil consumption is affected by the operational decrease due to wear of the ICE bearings, the action of centrifugal forces, at an unfavorable ratio of which the channel can "dynamically lock" and the oil flow ruptures into the connecting rod bearing.

\section{Conclusions}

The thermal condition of the crankshaft bearings is one of the reasons for changing and improving the conditions for supplying and consuming oil to the connecting rod bearings of the engine. The study made it possible to establish the maximum pressure in the engine lubrication system at which the bearing hydrodynamics are preserved and additional thermal stresses and shape changes do not occur in the liners. Avoiding the reduction of pressure in the lubrication system below $0.25 \mathrm{MPa}$ allows you to save the hydrodynamics in the connecting rod bearings of the crankshaft, thereby eliminating their premature failure.

\section{Acknowledgments}

The work is performed according to the Russian Government Program of Competitive Growth of Kazan Federal University.

\section{References}

[1] A.S. Denisov. Analysis of the causes of operational damage to the connecting rod bearings of the KamAZ-740 engine/ A.S. Denisov, A.T. Kulakov// Engine building. 1981. No. 9. - pp. 37-40.

[2] A.A. Gafiyatullin. Ensuring the operability of connecting rod bearings of automotive engines by creating the continuity of the oil flow / A.A. Gafiyatullin. Dis. Cand. tech. sciences. Saratov, 2005. - 130 pages.

[3] N.I. Svetlichny. Improving the reliability of KamAZ engines by reducing the failure of connecting rod bearings in operation / N.I. Svetlichny. Dis. Cand. tech. sciences. Saratov. 2001, 157 pages.

[4] A.T. Kulakov, A.T. A.T. Barylnikova, A.A. Gafiyatullin. "Providing normal conditions of lubricating of diesel engine during its operation”.// IOP Conference Series: Materials Science and Engineering. - Volume 69, 2014, p.012027.

[5] A.T. Kulakov, A.T. A.T. Barylnikova, A.T. Kulakov. "Adaptive system of supplying lubricant to the internal combustion engine” IOP Conf. Series: MaterialsScienceandEngineering. Vol. 240 (2017) 012010.

[6] A.T. Kulakov. Improving the reliability of automotive diesel engines by improving the process of lubrication, cleaning and repair technology of the main elements: diss. ... Dr. tech. Sciences: 05.20.03 / A.T. Kulakov. Saratov, 2007 .- 558 pages.

[7] M. A. Grigoriev. Ensuring engine reliability / M.A. Grigoryev, V.A. Doletsky. M .: Publishing house of standards, 1978, - 324 pages.

[8] A. Schillinq. Les huiles pour Motuvs et le qraissage des Moteuvs, Vol. II, 1962.

[9] A.T. Barylnikova. Increasing the resource of automobile engines by stabilizing the lubrication mode of connecting rod bearings in operation: diss ... cand. tech. Sciences: 05.22.10 // A.T. Barylnikova - Orenburg. 2013 - 140 pages.

[10] I.A. Sakhapov. Improving the reliability of automotive engines by reducing the deformation of the connecting rod bearings / I.A. Sakhapov. Dis. Cand. tech. sciences. Saratov. 2009 .- 143 pages.

[11] V.N. Nikishin. Friction bearings in automobiles and engines: a training manual / V.N. Nikishin; K.G. Belokon, S.V. Sibiryakov: FSBEI HPE "Kam. state engineer-econ. Acad. "- Naberezhnye Chelny: Publishing House of the Kama State. engineer-econ. Acad., 2012. -213 pages. 